\title{
Expression of Bacillus Protease (Protease BYA) from Bacillus sp. Y in Bacillus subtilis and Enhancement of Its Specific Activity by Site-Directed Mutagenesis - Improvement in Productivity of Detergent Enzyme-
}

\author{
Seiichi Tobe, ${ }^{* a}$ Hisao Shimogaki, ${ }^{b}$ Motoyasu Ohdera, ${ }^{c}$ Yoshio Asai,${ }^{c}$ Kenkichi Oba, ${ }^{d}$ \\ Masanori IWAma, ${ }^{e}$ and Masachika IRIE ${ }^{f}$ \\ ${ }^{a}$ Household Research Laboratories No. 1, Household Products Division, Lion Corporation; 7-13-12 Hirai, Edogawa-ku, \\ Tokyo 132-0035, Japan: ${ }^{b}$ Pharmaceutical Research Laboratories No. 1, Pharmaceutical Products Division, Lion \\ Corporation; ${ }^{c}$ Biological Science Research Center, Lion Corporation; 100 Tajima, Odawara, Kanagawa 256-0811, Japan: \\ ${ }^{d}$ Research \& Technology Headquarters, Lion Corporation; 7-13-12 Hirai, Edogawa-ku, Tokyo 132-0035, Japan: \\ ${ }^{e}$ Department of Materials Engineering, Nagaoka National College of Technology; 888 Nishikatakaichou, Nagaoka, \\ Niigata 940-8532, Japan: and ${ }^{f}$ Department of Applied Microbiology, Faculty of Pharmaceutical Sciences, Hoshi \\ University; 2-4-41 Ebara, Shinagawa-ku, Tokyo 142-8501, Japan.
}

Received July 13, 2005; accepted October 12, 2005; published online October 14, 2005

\begin{abstract}
An attempt was made to express protease BYA produced by an alkalophilic Bacillus sp. Y in Bacillus subtilis by gene engineering methods. The gene encoding protease BYA was cloned from Bacillus sp. Y, and expression vector pTA71 was constructed from the amylase promoter of Bacillus licheniformis, DNA fragments encoding the open reading frame of protease BYA, and pUB110. Protease BYA was secreted at an activity level of $5100 \mathrm{APU} / \mathrm{ml}$ in the common industrial culture medium of Bacillus subtilis transformed with pTA71. We then attempted to increase the specific activity of protease BYA by site-directed mutagenesis. Amino acid residue Ala29 next to catalytic Asp30 was replaced by one of three uncharged amino acid residues (Val29, Leu29, Ile29), and each mutant enzyme was expressed and isolated from the culture medium. Val29 mutant enzyme was secreted at an activity level of greater than $7000 \mathrm{APU} / \mathrm{ml}$ in culture medium, and its specific activity was 1.5-fold higher than that of the wild-type enzyme. Other mutant enzymes had specific activity similar to that of the original one and were less stabile than the wild-type enzyme. It can be thought that the substitution at amino acid residue 29 affects the level of activity and stability of protease BYA.
\end{abstract}

Key words protease BYA; subtilisin; expression; Bacillus; bacteriolysis; detergent protease

Subtilisins produced by genus Bacillus belong to the general class of serine proteases, they all share the active site (Ser, His, and Asp, respectively). ${ }^{1}$ Some subtilisins, represented by subtilisin Carlsberg from Bacillus licheniformis, are added to detergents products to remove soil effectively. ${ }^{1-4)}$ They are required to be stable in detergent solutions containing alkali and surfactants, and stable under high-temperature washing conditions. ${ }^{5)}$ Shimogaki et al. isolated a subtilisin called Bacillus protease BYA produced by an alkalophilic strain designated Bacillus sp. Y (FERM-8088). ${ }^{6}$ It retains $90 \%$ of its protease activity after $30 \mathrm{~min}$ in $0.1 \mathrm{~N}$ $\mathrm{NaOH}$ solution, $80 \%$ after $4 \mathrm{~h}$ in sodium linear alkylbenzene sulfonate solution, and $90 \%$ after $10 \mathrm{~min}$ at $60{ }^{\circ} \mathrm{C}$, whereas subtilisin Carlsberg completely loses its activity under the same conditions. Additionally, protease BYA shows bacteriolytic activity. ${ }^{7}$ It lysised gram-negative bacteria representing Pseudomonas aeruginosa, and some gram-positive bacteria like Staphylococcus aureus well, whereas subtilisin Carlsberg hardly lysised them. Bacteriolytic activity of protease BYA is superior to that of Deozyme,$^{8)}$ one of subtilisin known as superior bateriolytic enzyme, in out of $40^{\circ} \mathrm{C}$. It is believed that protease BYA contributes to improvement of sanitation by its detergency and bacteriolytic activity. From the standpoint of application, it is important to express it by gene engineering. In this study, we attempted to clone protease BYA gene, express it in Bacillus sublitis by molecular cloning, and enhance the specific activity of protease BYA by site-directed mutagenesis.

* To whom correspondence should be addressed. e-mail: seto@lion.co.jp

\section{MATERIALS AND METHODS}

Strains Bacillus sp. Y (FERM-8088), Bacillus licheniformis ATCC14580, and Escherichia (E.) coli HB101, JM109, GM2163 were used for gene cloning. Bacillus subtilis 1012 (FERM-7168), a variant of Bacillus subtilis Marburg 168 that secretes a little of its protease, subtilisin E, by mutation, was used as a host for expression of protease BYA.

DNA Probes and Primers DNA probes and primers shown in Table 1 were synthesized with a DNA synthesizer (Applied Bio System 381A). The DNA probes (a) and (b) were designed based on the amino acid residues at the N-terminal (Asn-Pro-Val-Ala-Arg-Gly-Ile-Val-Lys-Ala-Asp-ValAla-Gln-Asn-Asn-Tyr-Gly-Leu-Tyr-Gly) ${ }^{6}$ ) and one of the lysylendopeptidase digestion peptides (Lys-Tyr-Ala-Tyr-MetGly-Gly-Thr-Ser-Met-Ala-Thr) that containing the common amino acid sequence around the active site of subtilisin. They were synthesized by the deoxyinosine method $^{9)}$ with gamma 32P-ATP (Amersham).

Cloning of Protease BYA Gene Most of the methods used for molecular cloning were based on those of Maniatis et al. ${ }^{10)}$ Bacillus sp. $\mathrm{Y}$ was grown aerobically at $30^{\circ} \mathrm{C}$ overnight in nutrient broth (Kyokutouseiyaku) containing $\mathrm{Na}_{2} \mathrm{CO}_{3} 10 \mathrm{~g} / \mathrm{l}$. Chromosomal DNA was prepared essentially as described by Saito and Miura. ${ }^{11)}$ After digestion with restriction enzymes, the fragments were separated by agarose gel electrophoresis. The gel was dehydrated, and agarosemembrane hybridization was performed using each of the DNA probes. DNA fragments that hybridized to each DNA probe were separated by agarose gel electrophoresis and col- 

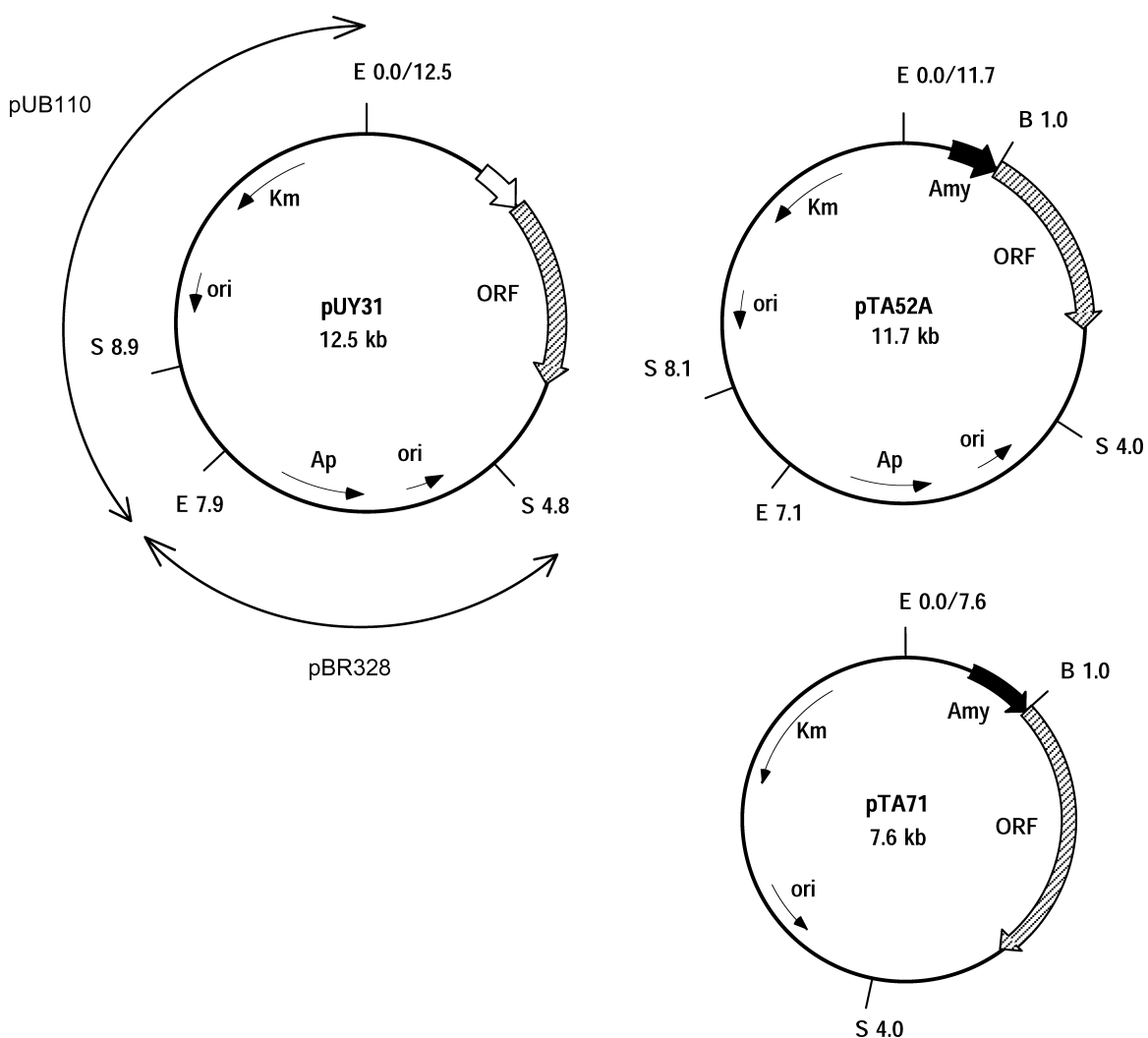

Fig. 1. Structure of Each Plasmid

The open arrow represents the deduced promoter region of the protease BYA gene. The solid arrows represent the promoter region of the Bacillus licheniformis amylase gene (Amy). The striped arrows represent the open reading frame of the protease BYA gene (ORF), E: Eco RI site; B: Bcl I site; S: Sph I site.

lected by the DEAE paper method. ${ }^{10)}$ Each DNA fragment was ligated to plasmid vector pBR328 or pUC118 treated with each restriction enzyme and alkaline phosphatase, and the ligated DNA was used to transform E. coli. Plasmids extracted from transformants were hybridized with the use of each probe according to the Southern hybridization method. ${ }^{10)}$

Cloning of Amylase Promoter Gene Bacillus licheniformis was grown aerobically at $30^{\circ} \mathrm{C}$ overnight in nutrient broth (Kyokutouseiyaku). Chromosomal DNA was prepared essentially as described by Saito and Miura. ${ }^{11)}$ After digestion with Eco RI, these fragments were ligated to pUC118 treated with Eco RI and alkaline phosphatase. E. coli transformed with the ligated DNA was incubated on Luria agar containing $10 \mu \mathrm{g} / \mathrm{ml}$ of ampicillin and $1 \%$ potato starch, and the colonies were examined for a halo of digested potato starch.

Construction of Expression Vectors Plasmids to express protease BYA were constructed as shown in Fig. 1. pUY31 was constructed from approximately $4.8 \mathrm{kbp}$ DNA fragment encoding the protease BYA gene, pBR328, and pUB110. ${ }^{12)}$ The $\mathrm{Bcl}$ I site (TGATCA) was created at the $1014 \mathrm{bp}$ of amylase gene shown in Figs. 2 and 3 with primer (c) shown in Table 1 by site-directed mutagenesis. The $\mathrm{Bcl}$ I sites were also created in $200-216 \mathrm{bp}$ region of the protease BYA gene with primer (d), (e) and (f) as shown in Figs. 3 and 4. pTA52A was constructed from pBR328, pUB110, and DNA fragments created with primer (c), (d). pTA52B and pTA52C were also constructed as well as pTA52A with primer (e) and (f) shown in Fig. 3. To do so efficiently, the
$\mathrm{Bcl}$ I site at $223 \mathrm{bp}$ upstream of the amylase promoter shown in Fig. 2 was deleted with primer ( $\mathrm{g}$ ) by site-directed mutagenesis, and the Eco RI site (GAATTC) of the protease BYA gene, at $1190 \mathrm{bp}$ shown in Fig. 4, was also deleted with primer (h), which made no alternation in the amino acid sequence of protease BYA. pTA71 was derived from shortening of pTA52A.

DNA Sequencing and Site-Directed Mutagenesis The restriction fragments to be sequenced were subcloned into pUC118 or pUC119, and ssDNA of each fragment was prepared using M13K07 phage. ${ }^{13)}$ DNA sequencing by the chain-termination method was performed according toSanger. ${ }^{14)}$ Both strands of the region analyzed were sequenced. The amino acid sequences of protease BYA and other proteases were aligned with DDBJ. ${ }^{15)}$ Site-directed mutagenesis was carried out according to the method of Kunkel et al., ${ }^{16}$ using a Muta Gene in vitro mutagenesis kit (BioRad). Each mutation was confirmed by DNA sequence analysis according to Sanger. ${ }^{14)}$

Expression of Proteases and Enzymatic Analysis Bacillus subtilis 1012 was transformed as described by Chain. ${ }^{17)}$ Bacillus subtilis 1012 transformed with a plasmid vector was grown aerobically at $33^{\circ} \mathrm{C}$ for approximately $90 \mathrm{~h}$ in common industrial culture medium containing $20 \mathrm{~g}$ of soluble starch, $20 \mathrm{~g}$ of polypepton $\mathrm{S}$ (Daigoeiyou), $5 \mathrm{~g}$ of $\mathrm{K}_{2} \mathrm{HPO}_{4}, 0.2 \mathrm{~g}$ of $\mathrm{MgSO}_{4} \cdot 7 \mathrm{H}_{2} \mathrm{O}, 50 \mathrm{mg}$ of kanamycin sulfate per liter, $\mathrm{pH}$ 7.5. Protease BYA and mutant enzymes secreted into the culture medium were purified, and their specific activity was measured as described Shimogaki et al. ${ }^{6}$ The amount of enzyme that liberated $1 \mu \mathrm{g}$ of tyrosine per min 


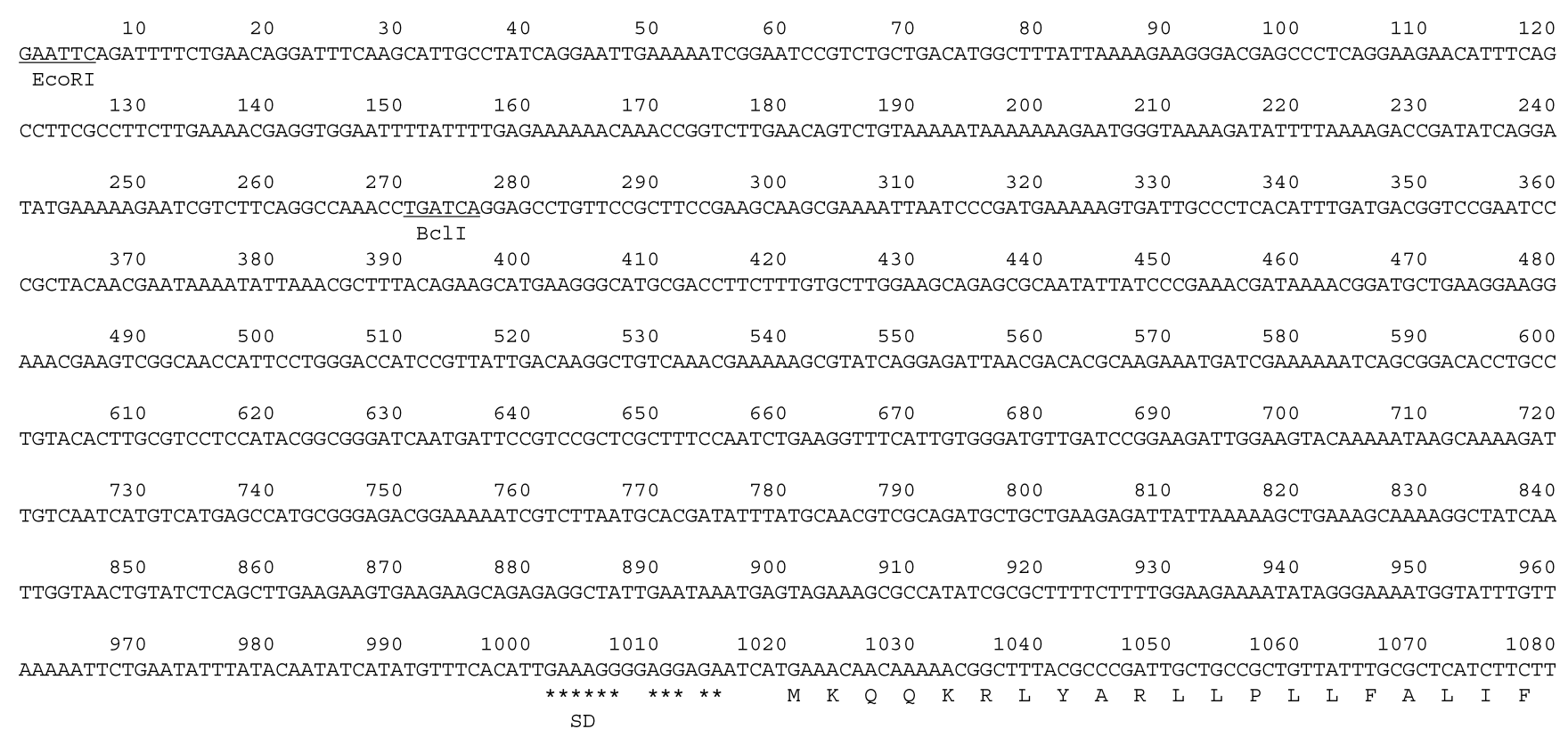

Fig. 2. Nucleotide Sequence of the Amylase Gene of Bacillus licheniformis

The putative Shine-Dalgarno sequence (SD) is indicated by the stars. Amino acids are represented by their single-letter code.

$$
\begin{aligned}
& \text { Amylase gene original ; - TTTCACATTGAAAGGGGAGGAGAATCATGAAACAACAAAAACGGCTTT- } \\
& \text { PTA52A ; - TTTCACATTGAAAGGGGAGGATGATCAATGAAGGGGAAAAAAAGAGTA- } \\
& \text { pTA52B ; - TTTCACATTGAAAGGGGAGGATGATCAGAAATGAAGGGGAAAAAAAGA - } \\
& \text { pTA52C ; -TTTCACATTGAAAGGGGAGGATGATCAGTTGAGGAGAAATGAAGGGGA- }
\end{aligned}
$$

Fig. 3. Construction of $\mathrm{Bcl}$ I Sites in the Amylase Gene and the Protease BYA Gene

The putative Shine-Dalgarno sequence (SD) is indicated by stars. Initial codons are underlined. DNA fragments of the protease BYA gene are in bold print

Table 1. DNA Probes and Primers Designed for Cloning and Site-Directed Mutagenesis
(a) 5'-CCATA(A/G)TT(A/G)TT(T/C)TGIGCIACATCIGC-3'
(b) 5'-GTICCICCCATATAIGC(A/G)TA(T/C)TT-3'
(c) 5'-TGTTGTTTCATGATCATCCTCCCCTTTCAA-3'
(d) 5'-TTTCCCCTTCATTGATCA TCAACTCCTCAT-3'
(e) 5'-TTTCCCCTTCATTTCTGATCAACTCCTCAT-3'
(f) 5' -TTTCTCCTCAACTGATCATCTTCATTCATT-3'
(g) 5'-GGAACAGGCTCCTGGTCAGGTTTGGCCTGA-3'
(h) 5'-CCAAGAGTTAGTATGGATTCTTGCTCCAGC-3'
(i) 5'-CTAGTTGCAGTAGTTGACACAGGCTTAGAT-3'
(j) 5'-AACTAGTTGCAGTACTTGACACAGGCTTAG-3'
(k) 5'-CTAGTTGCAGTAATTGACACAGGCTTAGAT-3'

Substitutions of the original nucleotides sequence are underlined.

under the condition described by Shimogaki et al. ${ }^{6)}$ was defined as one unit of alkaline protease activity (1 APU). The heat-, alkali-, and surfactant-stability of the proteases was evaluated according to Shimogaki et al. ${ }^{6}$ Each protease (1000 APU/ml) was incubated under various conditions.

\section{RESULTS}

Cloning of Protease BYA Gene Several DNA probes were designed, and two DNA probes (a) and (b) that clearly hybridized to chromosomal DNA were used for cloning.
DNA probe (a) always hybridized to an approximately $2.8 \mathrm{~kb}$ Eco RI or $1.2 \mathrm{~kb} \mathrm{Xba}$ I fragment. DNA probe (b) always hybridized to an approximately $2.0 \mathrm{~kb} E c o$ RI or $1.2 \mathrm{~kb} X b a \mathrm{I}$ fragment. Each DNA fragment was collected and ligated to plasmid vector pBR328 or pUC118, and the ligated DNA was used to transform E. coli. Each plasmid of 500 transformants was prepared and hybridized by the Southern hybridization method with each of the probes. A few plasmids from each transformant reacted strongly with DNA probe (a) or (b). Plasmids containing each fragment to which the labeled probes hybridized were detected and named pYT101 (2.8 kb, Eco RI), pYB002 (2.0 kb, Eco RI), and pYX001 $(1.2 \mathrm{~kb}, X b a \mathrm{I})$. The results of sequence analysis of clones and the deduced amino acid sequence are shown in Fig. 4. The $21 \mathrm{~N}$-terminal residues and 12 residues in the vicinity of the active site identical with those of mature protease BYA are underlined. The open reading frame of the protease BYA gene comprised 1905 nucleotides. The deduced amino acid sequence indicated that protease BYA consists of 635 amino acid residues and has a molecular mass of $67678 \mathrm{Da}$. The mature protease BYA consists of 433 amino acid residues (between +1 to +433 ), and has a molecular mass of 45573 Da.

Cloning of Amylase Promoter A transformant that formed a halo was obtained from approximately 2000 colonies in a chromosome library of Bacillus licheniformis in 


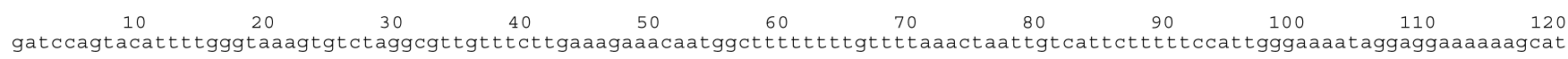

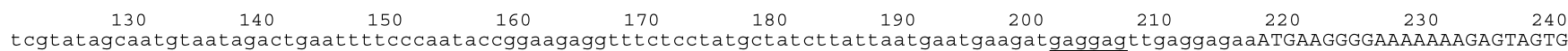
$\mathrm{M}$
$\mathrm{V} \quad \mathrm{V}$

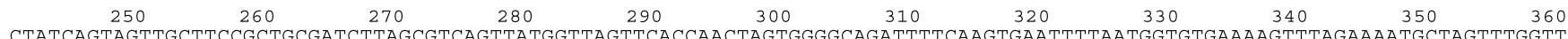

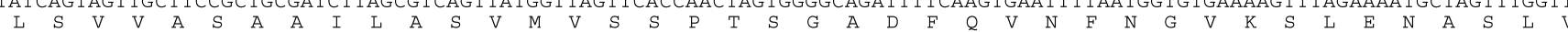

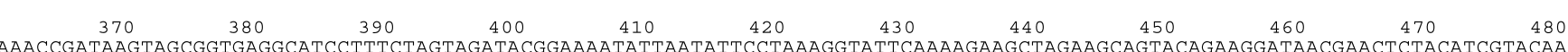
AAACCGATAAGTAGCGGTGAGGCATCCTTTCTAGTAGATACGGAAAATATTAATATTCCTAAAGGTATTCAAAAGAAGCTAGAAGCAGTACAGAAGGATAACGAACTCTACATCGTACAA

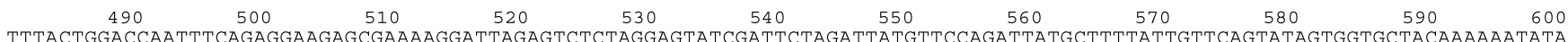

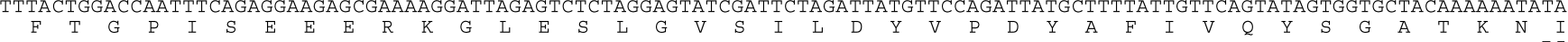
$\begin{array}{cccccccc}610 & 620 & 630 & 640 & 650 & 660 & 670 & 680 \\ \text { AGTACTTTACATTCTGTTGAGAACGTACAACCATTTTTACCATTATATAAAATTGATCCTGAGCTTTTAACGAAAGGTGCTTCCCAGCTTGTTCAAGCGGTTATTTTAAATACAAAACAC }\end{array}$

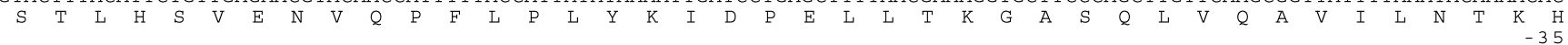
$\begin{array}{lllllllll}730 & 740 & 750 & 760 & 770 & 780 & 790 & 800 & 810\end{array}$ GAAAATAAAAACATGAAATTTACCGGTTTAGATGAGATCGTTCAATATGCTGCAAATAATGATGTGCTTTATATATCACCAAAGCCCGAGTATGAGCTAATGAATGATGTAGCAAGAGGG

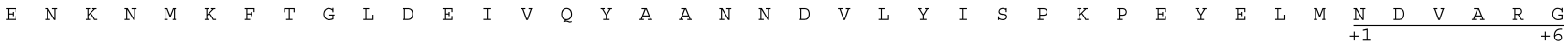

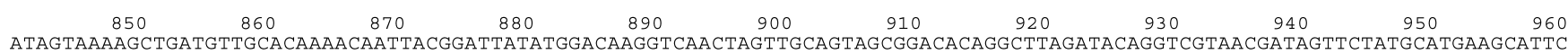

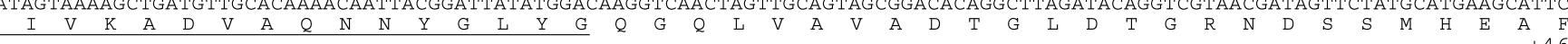

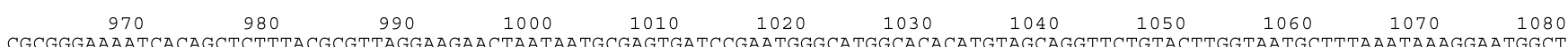
CGCGGGAAAATCACAGCTCTTTACGCGTTAGGAAGAACTAATAATGCGAGTGATCCGAATGGGCATGGCACACATGTAGCAGGTTCTGTACTTGGTAATGCTTTAAATAAAGGAATGGCT

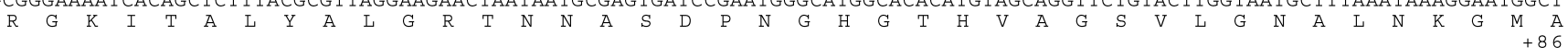

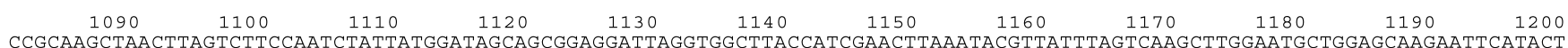

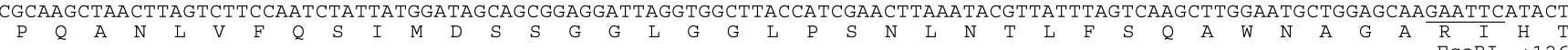

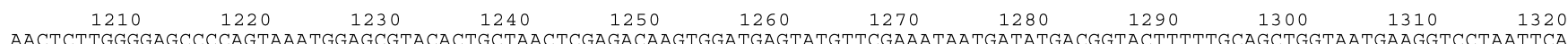

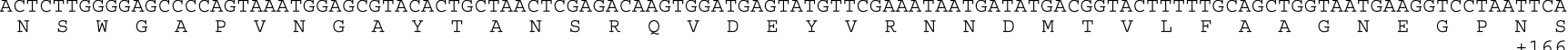

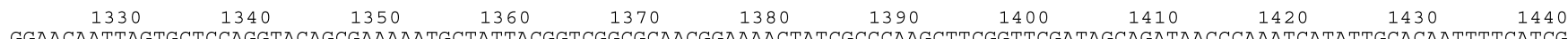

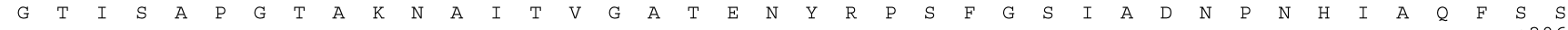
$\begin{array}{lllllllll}1450 & 1460 & 1470 & 1480 & 1490 & 1500 & 1510 & 1520 & 1530\end{array}$ AGAGGAGCTACGAGGGATGGACGAATTAAGCCTGACGTAACAGCTCCTGGAACATTTATTTTATCAGCACGTTCTTCCTTAGCTCCAGACTCTTCGTTTTGGGCGAATTATAACAGTAAA

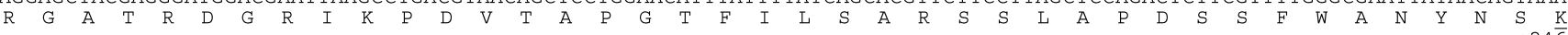

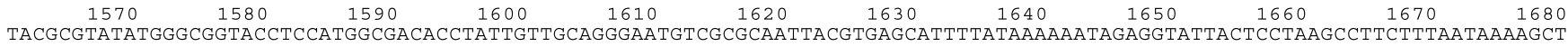

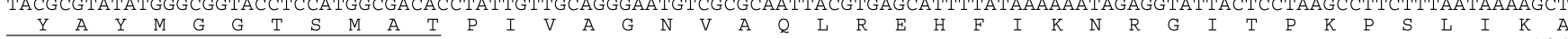
$\begin{array}{lllllllll}1690 & 1700 & 1710 & 1720 & 1730 & 1740 & 1750 & 1760 & 1770\end{array}$ GCACTTATCGCTGGTGCTACTGATGTTGGTTTAGGATATCCTAGTGGTGACCAAGGCTGGGGGCGTGTTACTCTAGATAAATCGTTAAATGTAGCGTATGTCAATGAAGCAACTGCATTA

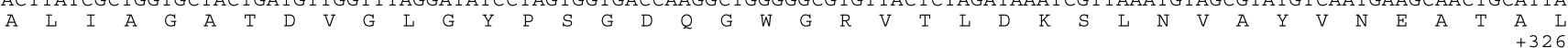
$\begin{array}{rrrrrrrrrr}1810 & 1820 & 1830 & 1840 & 1850 & 1860 & 1870 & 1880 & 1890 & 1900\end{array}$ GCCACAGGACAAAAAGCAACGTATTCGTTCCAAGCACAAGCGGGTAAACCTTTAAAAATCTCGTTAGTATGGACAGATGCTCCTGGAAGTACAACTGCATCTTATACACTAGTTAATGAT

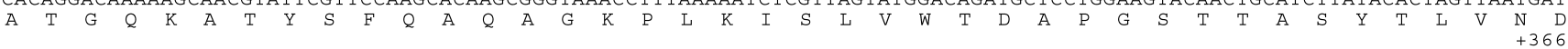

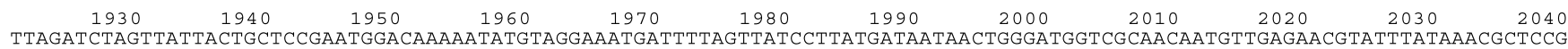

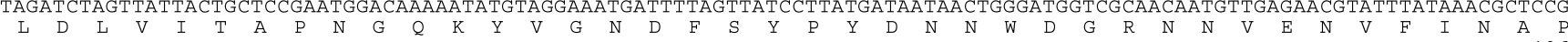

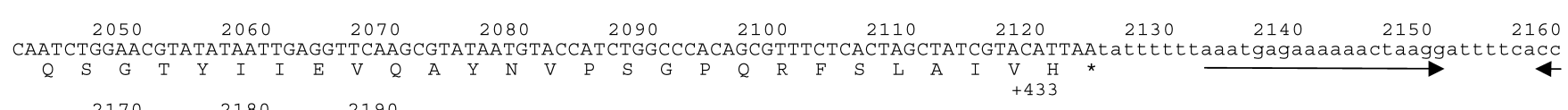
$\begin{array}{ccc}2170 & 2180 & 2190 \\ \text { ttagttttctcatttgttcaacgattatatttttccacgactatggaagcta }\end{array}$

Fig. 4. Nucleotide Sequence of the Protease BYA Gene, and the Deduced Amino Acid Sequence of the Protein

A putative Shine-Dalgarno sequence (SD) and a transcriptional termination signal (arrows) are indicated. Amino acids are represented by their single-letter code. The open reading frame extends from Met $(-202)$ to His $(+433)$. The $21 \mathrm{~N}$-terminal residues $(+1-+21)$ and 12 residues in the vicinity of the active site $(+246-+257)$ identical with those of mature protease BYA are underlined.

E. coli. Plasmid (pTA01) including an approximately $3.5 \mathrm{kbp}$ Eco RI fragment was extracted from the transformant. The sequence in the vicinity of the amylase promoter in pTA01 was determined and is shown in Fig. 2. The sequence was found to have $99 \%$ homology with the sequence of the amy- lase promoter reported by Yuuki et al. ${ }^{18)}$

Expression of Protease BYA Bacillus subtilis 1012 was transformed with pUB110, pUY31, pTA52A, pTA52B, pTA52C, or pTA71, and incubated in culture medium. Shown as Table 2, a transformant carrying pUB110 secreted 
Table 2. The Amounts of Protease BYA Produced by Transformants Carrying Various Recombinant Plasmids

\begin{tabular}{lc}
\hline \multicolumn{1}{c}{ Plasmids } & APU/ml \\
\hline pUB110 & 320 \\
pUY31 & 370 \\
pTA52A & 3400 \\
pTA71 & 5100 \\
pTA71 (Val29) & 7200 \\
\hline
\end{tabular}

Alkaline protease units (APU/ml) were measured $\left.{ }^{6}\right)$ in the culture medium of Bacillus subtilis 1012 carrying each plasmid.

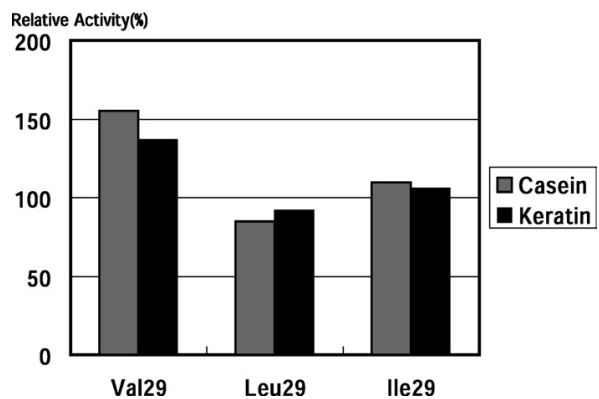

Fig. 5. Specific Activity of Protease BYA Mutants (Va129, Leu29, Ile29) in Comparison with Protease BYA (Ala29)

The concentrations of each enzyme were made uniform. Their activity was measured with casein or keratin as the substrate, and their specific activity was evaluated by comparison with Ala29.

$320 \mathrm{APU} / \mathrm{ml}$ of alkaline protease in the culture medium, and a transformant carrying pUY31 secreted $370 \mathrm{APU} / \mathrm{ml}$. On the other hand, $3400 \mathrm{APU} / \mathrm{ml}$ of alkaline protease was secreted by a pTA52A transformant, and $5100 \mathrm{APU} / \mathrm{ml}$ of alkaline protease was secreted by a pTA71 transformant. The secreted protein was purified by Shimogaki's method, ${ }^{6)}$ and detected as single band which has approximately $45000 \mathrm{Da}$ by SDS-PAGE (data not shown). Its relative activity was approximately $16000 \mathrm{APU} / \mathrm{mg}$ corresponded to that of protease BYA from Bacillus sp. Y. By contrast, no putative protease BYA was detected in the culture medium of transformants carrying pTA52B or pTA52C.

Site-Directed Mutagenesis and Enzymatic Analysis Val29, Leu29, and Ile29 mutant protease BYA enzymes were generated by site-directed mutagenesis with primers (i), (j), and (k), respectively. Protease BYA (Ala29 enzyme) and its mutants were produced by pTA71 or by substitution at the Ala29 site, a transformant carrying pTA71 encoding Val29 mutant gene secreted $7200 \mathrm{APU} / \mathrm{ml}$ of alkaline protease in the culture medium shown in Table 2 . The protease activity of culture medium increased approximately 1.4 fold greater than that of Ala29 enzyme. Each enzyme was purified by the method described by Shimogaki et al., ${ }^{6}$ and its activity against casein and keratin was measured at the same enzyme concentrations, and their specific activity was measured in comparison with the Ala29 enzyme. As shown in Fig. 5, the results revealed approximately $150 \%$ greater specific activity of the Val29 mutant for each of the substrates as Ala29 enzyme, and that the Leu29 mutant and Ile29 mutant had activity nearly equal to Ala29 enzyme. Testing of the alkali resistance of each enzyme revealed residual activity of the Ala29 enzyme of approximately $900 \mathrm{APU} / \mathrm{ml}(90 \%)$, approximately $80 \%$ for the Val29 mutant, but only approximately $40 \%$ or

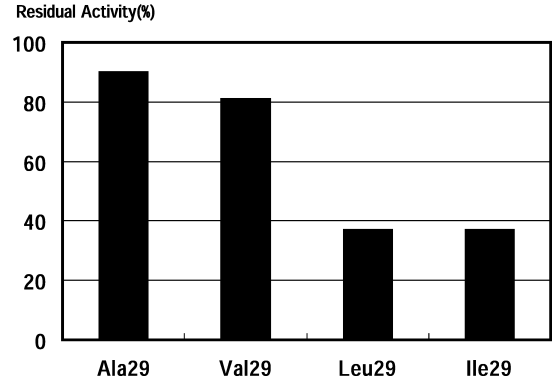

Fig. 6. Alkaline Stability of Protease BYA (Ala29) and Its Mutants (Va129, Leu29, Ile29)

Each protease $(1000 \mathrm{APU} / \mathrm{ml})$ was incubated in $0.1 \mathrm{~N} \mathrm{NaOH}$ at $35^{\circ} \mathrm{C}$ for $30 \mathrm{~min}$, residual activity was measured by the described method. ${ }^{6}$

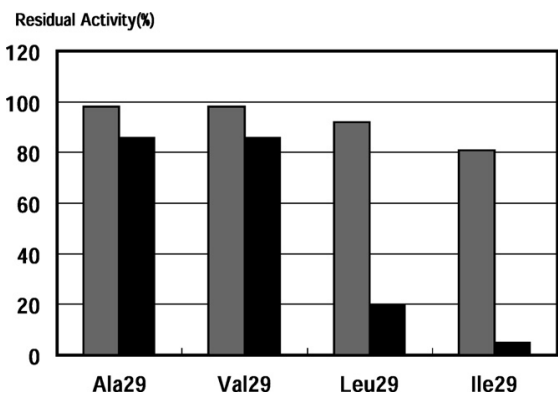

Fig. 7. Stability of Protease BYA (Ala29) and Its Mutants (Va129, Leu29, Ile29) in Surfactant Solutions

Proteases $(1000 \mathrm{APU} / \mathrm{ml})$ were incubated at $35^{\circ} \mathrm{C}$ for $20 \mathrm{~h}$ in $50 \mathrm{~mm}$ borate buffer (pH 10.5) containing each surfactant, and residual activity was measured by the described method. ${ }^{\text {) }}$ Gray bars indicate residual activity in sodium dodecyl sulfate (SDS) and solid bars indicate residual activity in sodium linear alkylbenzene sulfonate (LAS).

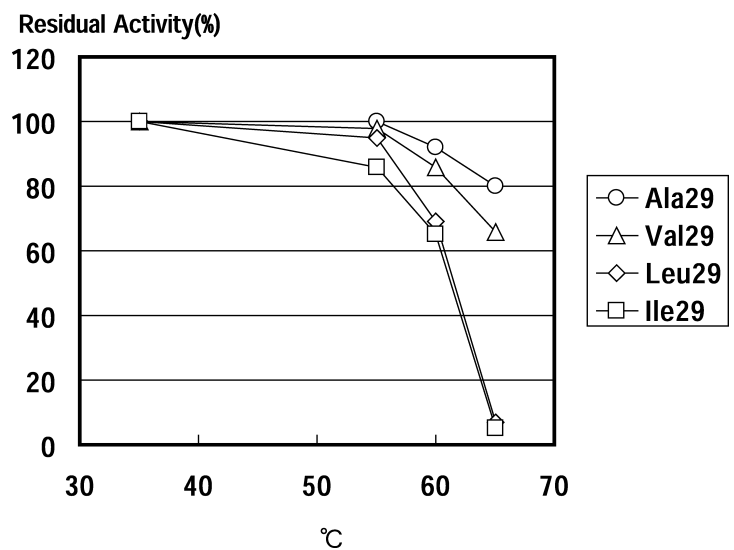

Fig. 8. Thermo-Stability of Protease BYA (Ala29) and Its Mutants (Val29, Leu29, Ile29)

Proteases $(1000 \mathrm{APU} / \mathrm{ml})$ were incubated at each temperature for $10 \mathrm{~min}$ in $50 \mathrm{~mm}$ borate buffer ( $\mathrm{pH} 10.5)$. Residual activity was measured by the described method. ${ }^{6}$

less for the Leu29 mutant and Ile29 mutant (Fig. 6). The surfactant resistance of each enzyme was evaluated by comparing its residual activity after incubation in each surfactant solution for $20 \mathrm{~h}$ at $35^{\circ} \mathrm{C}$ with its initial activity. The residual activity of each enzyme in sodium dodecyl sulfate (SDS) was $80 \%$ or more, but the residual activity of the Ala29 enzyme and Val29 mutant in linear alkyl benzene sulfate (LAS) was approximately $80 \%$, as opposed to $20 \%$ or less for the Leu 29 mutant and Ile29 mutant (Fig. 7). The heat resistance of each enzyme was evaluated by calculating its residual activity after incubation at different temperatures for $10 \mathrm{~min}$ as a per- 
centage of its residual activity at $35^{\circ} \mathrm{C}$. The residual activity of all of enzymes was lower at $60^{\circ} \mathrm{C}$ and above. The residual activity of the Ala 29 enzyme was approximately $80 \%$, as opposed to approximately $60 \%$ for the Val2 9 mutant, and the activity of the Leu 29 mutant and the Ile 29 mutant was almost completely lost at $65^{\circ} \mathrm{C}$ (Fig. 8).

\section{DISCUSSION}

Amino Acid Sequence of Protease BYA The amino acid sequence of protease BYA was compared with that of several other subtilisins in Fig. 9. The amino acid sequence of protease BYA is approximately 160 residues longer than that of typical subtilisins, which consist of approximately 270 amino acid residues and have molecular masses of approximately $27000 \mathrm{Da}$, and most of the extra amino acids are concentrated at the C-terminal and in several short peptides inserted near the active site. It can be thought that the presence of the inserted sequence and the large C-terminal peptide shown in Fig. 9 may be responsible for its alkaliphilic nature, its surfactants-resistance, and heat stability, although there is no conclusive evidence.

We registered the nucleotide sequence of protease BYA with Gene-Bank (No. E03808; Sep. 29, 1997). Saeki et al. discovered a protease, protease $\mathrm{E}-1$, and registered its nucleotide sequence with Gene-Bank (No. AB046402; June 16, 2001). ${ }^{19)}$ As shown in Fig. 9, the amino acid sequence of protease E-1 is very similar to that of protease BYA. The only difference between them is 5 residues (amino acids no. +25 , $+63,+317,+328,+412)$. They also determined the DNA sequence of mature protease BYA and registered it with Gene-Bank (AB046404; Jan. 23, 2001) and they published

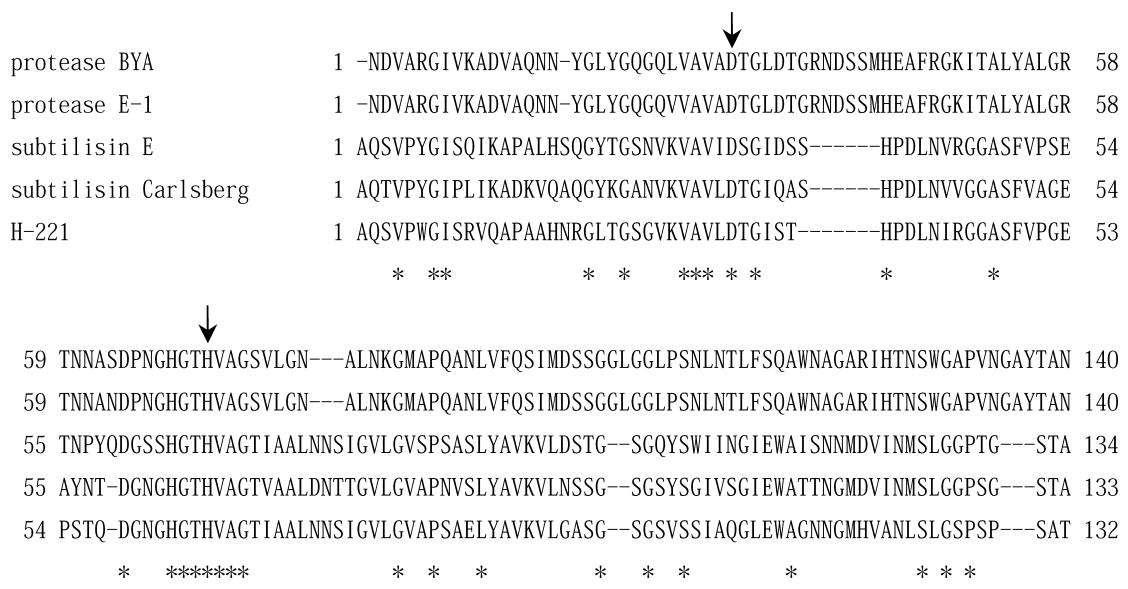

141 SRQVDEYVRNNDMTVLFAAGNEGPN-SGTISAPGTAKNAITVGATENYRPSFGSIADNPNHIAQFSSRGATRDGRIKPDVTAPG 223 141 SRQVDEYVRNNDMTVLFAAGNEGPN-SGTISAPGTAKNAITVGATENYRPSFGSIADNPNHIAQFSSRGATRDGRIKPDVTAPG 223 135 LKTVVDKAVSSGIVVAAAAGNEGSSGSTSTVGYPAKYPSTIAVGAVN-------------SSNQRASFSSAGSELDVMAPG 202 134 MKQAVDNAYARGVVVVAAAGNSGSSGNTNTIGYPAKYDSVIAVGAVD----------------SNSNRASFSSVGAELEVMAPG 201 133 LEQAVNSATSRGVLVVAASGNSGAG----SISYPARYANAMAVGATD------------------QNNNRASFSQYGAGLDIVAPG 196

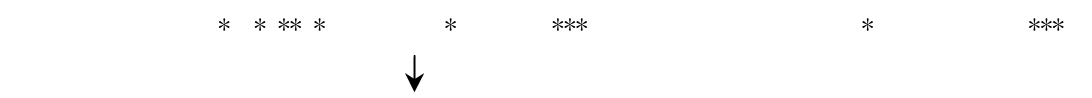

224 TFILSARSSLAPDSSFWANYNSKYAYMGGTSMATPIVAGNVAQLREHF IKNRGITPKPSLIKAALIAGATDVGLGYPSGDQGWGR 308 224 TF ILSARSSLAPDSSFWANYNSKYAYMGGTSMATPIVAGNVAQLREHF I KNRGITPKPSL I KAAL I AGATDVGLGYPSGDQGWGR 308 203 VSIQSTLP-----------_GTYGAYNGTSMATPHVAGAAALILSKHPTWTNAQVRDRLESTATYLGNSFYYGKGLINVQAAAQ 275 202 AGVYSTYP---_-_-_---_TSTYATLNGTSMASPHVAGAAALILSKHPNLSASQVRNRLSSTATYLGSSFYYGKGLINVEAAAQ 274 197 VNVQSTYP---------_GSTYASLNGTSMATPHVAGAAALVKQKNPSWSNVQIRNHLKNTATSLGSTNLYGSGLVNAEAATR 269 $* \quad * \quad * * * * * * * * * * \quad * \quad * \quad *$ 309 VTLDKSLNVAYVNEATALATGQKATYSFQAQAGKPLKISLVWTDAPGSTTASYTLVNDLDLVITAPNGQKYVGNDFSYPYDNNWD 393 309 VTLDKSLNVAYVNEATALTTGQKATYSFQTQAGKPLKISLVWTDAPGSTTASYTLVNDLDLVITAPNGQKYVGNDFSYPYDNNWD 393

394 GRNNVENVFINAPQSGTYIIEVQAYNVPSGPQRFSLAIVH 433 394 GRNNVENVFINAPQSGTYTIEVQAYNVPSGPQRFSLAIVH 433

Fig. 9. Primary Structural Alignment of Protease BYA, Protease E-1, ${ }^{19)}$ Subtilisin E, ${ }^{20)}$ Subtilisin Carlsberg, ${ }^{24)}$ and H-221 ${ }^{25)}$

Each amino acid sequence is numbered starting with the N-terminal residue of the mature protein. Amino acids are represented by their single-letter code. Asterisks indicate amino acids that were identified as present in all of the sequences. Arrows point to the catalytic triad. 
amino acid sequences. ${ }^{19)}$ The DNA sequence of the mature protease BYA reported by Saeki et al. also differs from ours by 4 nucleotides (nucleotides no. 896 to G, 1260 to A, 1724 to A, 1756 to A).

Expression of Protease BYA E. coli transformed with recombinant plasmid encoding the whole protease BYA gene expressed approximately $10 \mathrm{APU} / \mathrm{ml}$ of protease BYA into the culture medium. The amount produced was very low, about $1 / 30$ of the amount produced by Bacillus sp. Y (data not shown). We therefore attempted to express protease BYA in Bacillus subtilis 1012 as the host, one of the mutant strains of Bacillus subtilis Marburg 168. It produced a little amount of subtilisin E, and we detected $320 \mathrm{APU} / \mathrm{ml}$ of subtilisin E in culture medium of its transformant with pUB110. First, expression was attempted by connecting the approximately $4.8 \mathrm{kbp}$ DNA fragment encoding the protease BYA gene to pBR328 and pUB110 (pUY31). pUY31 is capable of replication in E. coli and genus Bacillus, but hardly any expression of protease BYA was observed. Since Bacillus sp. Y is an alkalophile, its regulatory mechanism of expression may be quite different from that of neutraphilic species of Bacillus. Since the homology between the deduced nucleotide sequence of the promoter region of protease BYA $(1-216 \mathrm{bp})$ and subtilisin $\mathrm{E}^{20)}$ is less than $50 \%$, recognition of the protease BYA gene promoter in the host, Bacillus subtilis may be concluded to be low. There is a possibility of the higher expression by exchanging promoter that could be recognized well in the host. We then searched for a promoter that would be capable of sufficient expression in Bacillus subtilis and would be easy to connect to the structural gene of protease BYA. Both protease BYA and the amylase gene from Bacillus licheniformis have sequences that can be easily created $\mathrm{Bcl}$ I site adjacent their initial codons respectively. Moreover, the amylase can be produced in large amounts and has been produced as a commercial enzyme. ${ }^{2}$ The $\mathrm{Bcl}$ I site was therefore constructed in each DNA fragment by site-directed mutagenesis, and after connecting amylase promoter and the structural gene, recombinant plasmids were constructed in order to express protease BYA. The transformant carrying pTA52A secreted $3400 \mathrm{APU} / \mathrm{ml}$ of alkaline protease. These results indicated that sufficient protease BYA can be expressed in Bacillus subtilis by replacing the promoter in common industrial culture medium. By contrast, hardly any expression of protease BYA was observed by transformants carrying pTA52B or pTA52C. As shown in Fig. 4, the distance between the SD and initial codon of pTA52A is the closest to that of the original amylase, and thus it appears necessary to make the SD-ATG initial codon distance as close as possible to the original distance in the amylase gene to achieve sufficient expression in Bacillus subtilis using the amylase promoter. Expression of protease BYA with pTA71 $(7.63 \mathrm{~Kb})$ was higher than with pTA52A $(11.8 \mathrm{~Kb})$. It can be indicated that the stability of the plasmid in a transformant was enhanced by miniaturization.

Site-Directed Mutagenesis of Protease BYA A number of studies on mutant subtilisins have been conducted by protein engineering. ${ }^{21)}$ Their 3-dimensional structure has been studied, and numerous results have been reported. Takagi et $a l^{22)}$ focused on amino acid Ile31, adjacent to Asp32, which is one of the amino acids that form the active site of subtilisin E, and they increased its specific activity $2-6$ fold by replacing its amino acid residues. Their findings suggested that amino acids in the vicinity of the active site are related in the reaction rate. Although protease BYA has been classified as a member of subtilisins, the same as subtilisin $\mathrm{E}$, the alkali, heat, and surfactant resistance of protease BYA appear to be greater than that of subtilisin E. Amino acid sequence of protease BYA was different from that of common subtilisin, such as subtilisin E shown in Fig. 9. However, the vicinity of the active site of protease BYA is highly homologous with that of subtilisin E. Based on this finding, by replacing the amino acid residues in the vicinity of the active site, it appeared possible to make the enzyme reactivity similar to that of subtilisin $\mathrm{E}$ and retain these characteristic resistance properties of protease BYA. We therefore focused on the Ala29 located next to Asp30, which has been deduced to constitute one of the active site of protease BYA, and compared changes in its specific activity when its amino acid residues were replaced. Since Ala is a hydrophobic amino acid, we replaced it with Val, Leu, and Ile, which are classified as hydrophobic amino acids. The results showed that the specific activity of the Val29 mutant for casein and keratin as substrates was 1.5 fold higher than that of Ala29 enzyme. It can be thought that the property indicates improvement in detergency of soils containing keratin such as stain of underwear. Since the specific activity of the Leu29 mutant and the Ile29 mutant hardly differs at all from that of the wild type, the Val29 mutant alone may enhance the reaction rate. In addition, each of the enzymes was also evaluated on the heat, surfactants, and alkali resistance that are characteristic of protease BYA. Val29 mutant showed almost the same resistance to that of Ala29, and Leu29 mutant and Ile29 mutant showed lower resistance to that of Ala29. Although the mechanism is unknown, it can be thought that the side chain of amino acid 29 forms hydrophobic core with other hydrophobic side chains in vicinity of active site, and the conformation of the hydrophobic core affects specific activity and resistances.

\section{CONCLUSION}

It has been demonstrated that it is possible to express protease BYA in Bacillus subtilis. Studying replacements in promoters with high expression efficiency, increases in vector copy number and stability, and changes in host proliferation and culture conditions may make it possible to increase productivity even more in the future.

In this study it was possible to increase the specific activity of protease BYA by protein engineering without losing hardly any of the resistance properties that are its important characteristics. In the future it may be possible to produce even better enzymes for detergents by further improving substrate specificity and resistance ability by protein engineering. Bacillus sp. Y also produces a small amount of another alkaline protease in culture medium. ${ }^{23)}$ It can be thought that its alkaline protease also be studied as well as protease BYA.

\section{REFERENCES AND NOTES}

1) Takagi H., Tanpakushitsu Kakusan Koso (Protein, Nucleic Acid, Enzyme), 37, 303-313 (1992).

2) Ee J. H., Misset O., Baas E. J., "Enzyme in Detergency," Marcel Dekker Inc., New York, 1997, pp. 61-230.

3) Murase M., J. Antibact. Antifung. Agents, 14, 473-483 (1986). 
4) Ikeda S., Sharyo M., Kurosaka R., Fragrance J., 2002 (12), 61—67 (2002).

5) Sakaguchi H., Ueno K., Yushi, 36, 52-56 (1983).

6) Shimogaki H., Takeuchi K., Nishino T., Ohdera M., Kudoh T., Ohba K., Iwama M., Irie M., Agric. Biol. Chem., 55, 2251-2258 (1991).

7) Tobe S., Watanabe T., Hama I., Iwama M., Irie M., J. Oleo Sci., 54, 595-600 (2005)

8) Tobe S., Nagoh Y., Watanabe T., Mukaiyama T., J. Oleo Sci., 54, 389-395 (2005).

9) Ohtsuka E., Matsuki S., Ikehara M., Takahashi Y., Matsubara K., J. Biol. Chem., 260, 2605-2608 (1985).

10) Maniatis T., Fritsch E. F., Sambrook J., "Molecular Cloning Second Edition," Cold Spring Harbor Laboratory Press, New York, 1982.

11) Saito H., Miura K., Biochim. Biophys. Acta, 72, 619-629 (1963).

12) McKenzie T., Hoshino T., Tanaka T., Sueoka N., Plasmid, 15, 93-103 (1986).

13) Messing J., Methods Enzymol., 101, 20-78 (1983).

14) Sanger F., Nicklen S., Coulson A. R., Proc. Natl. Acad. Sci. U.S.A., 74, 5463-5467 (1977).
15) DDBJ, http://www.ddbj.nig.ac.jp/Welcome-j.html

16) Kunkel T. A., Roberts J. D., Zakour R. A., Methods Enzymol., 154, 367-382 (1987).

17) Chang S. C., Cohen S. N., Mol. Gen. Genet., 168, 111-115 (1979).

18) Yuuki T., Nomura T., Tezuka H., Tsuboi A., Yamagata H., Tsukagoshi N., Udaka S., J. Biochem. (Tokyo), 98, 1147-1156 (1985).

19) Saeki K., Okuda M., Hatada Y., Kobayashi T., Ito S., Takami H., Horikoshi K., Biochem. Biophys. Res. Commun., 279, 313-319 (2000).

20) Stahl M. L., Ferrari E., J. Bacteriol., 158, $411-418$ (1984).

21) Takagi H., Nippon Nogeikagaku Kaishi, 71, 995-1002 (1997)

22) Takagi H., Morinaga Y., Ikemura H., Inouye M., J. Biol. Chem., 263, 19592-19596 (1988).

23) JP62-146594A (1987).

24) Jacobs M., Eliasson M., Uhlen M., Flock J. I., Nucleic Acids Res., 13, 8913-8926 (1985).

25) Takami H., Kobayashi M., Yamamoto M., Nakamura S., Aono R., Horikoshi K., Biosci. Biotechnol. Biochem., 56, 1455-1460 (1992). 